\title{
Influence of Ultrafine Natural Steatite Powder on Setting Time and Strength Development of Cement
}

\author{
K. Sudalaimani ${ }^{1}$ and M. Shanmugasundaram ${ }^{2}$ \\ ${ }^{1}$ Department of Civil Engineering, Thiagarajar College of Engineering, Thiruparankundram, Madurai, Tamilnadu 625015, India \\ ${ }^{2}$ Department of Civil Engineering, Vickram College of Engineering, Madurai, Tamilnadu 630561, India
}

Correspondence should be addressed to M. Shanmugasundaram; shanmugaresearch@gmail.com

Received 16 November 2013; Revised 29 January 2014; Accepted 9 February 2014; Published 11 March 2014

Academic Editor: Mohammad Mahroof-Tahir

Copyright (c) 2014 K. Sudalaimani and M. Shanmugasundaram. This is an open access article distributed under the Creative Commons Attribution License, which permits unrestricted use, distribution, and reproduction in any medium, provided the original work is properly cited.

\begin{abstract}
This paper deals with the setting time and pozzolanic activity of cement when ultra fine natural steatite powder (UFNSP) is used as replacement for cement. Initial setting time, final setting time, and mortar cube strength were studied, due to the replacement of ultra fine natural steatite powder with cement at $5 \%, 10 \%, 15 \%, 20 \%$, and $25 \%$ by mass of cement. The setting time of fresh cementbinder paste and compressive strength of mortar cubes are observed. Scanning electron microscopy (SEM) and X-ray diffraction (XRD) were applied to investigate the microstructural behaviour and chemical element distribution inside cement-binder matrix. Results indicate that the length of dormant period is shortened. The replacement of ultra fine natural steatite powder with cement reduces initial setting time, and final setting time and increases mortar cube compressive strength.
\end{abstract}

\section{Introduction}

Steatite is a type of metamorphic rock, largely composed of talc ore, rich in magnesium. It is composed of hydrated magnesium silicate: $\mathrm{Mg}_{3} \mathrm{Si}_{4} \mathrm{O}_{10}(\mathrm{OH})_{2}$. Steatite is the softest known mineral and listed as 1 on the Mohs hardness scale. It is already used in paint industry, particularly in marine paints and protective coatings. This is used in ceramics due to its high resistivity, very low dielectric loss factor, and good mechanical strength. Addition of steatite powder increases the viscosity and mechanical properties of feed stock. The thermal properties of steatite are also good [1]. Massive steatite cut into panels is used for switchboards, for acid proof tabletops in laboratory, laundry, and kitchen sinks, and in tubs and tanks, as well as for lining alkali tanks in paper industry. Due to its high melting point $\left(1630^{\circ} \mathrm{C}\right)$ [2], steatite can be used in refractory and fire places. It is also quite useful in sculpturing. When fabricated by a combined method of high energy ball milling, cold pressing, and sintering, it improves thermal properties of ceramics $[3,4]$. Cement mortars prepared with steatite particles have been investigated for restoration of sculptures and other craftworks. It was observed that the highest compressive strength ( $43 \mathrm{MPa})$ and lowest apparent porosity $(0.19 \%)$ are achieved when steatite particles are coarser (ranging from $1.41 \mathrm{~mm}$ to $0.42 \mathrm{~mm}$ ), and $40 \%$ of polymeric phase is employed [5]. A special cementbased mortar containing additions of fine powder waste from mineral extraction of steatite has been developed in Brazil, as a composite material for restoration of steatite elements [6]. The steatite is mostly used in electrotechnics. Stabilization of protoenstatite in steatite body is achievable by the development of small crystals [7]. Improper selection of parameters led to undesired problems such as separation of the powderbinder mixture and formation of collapses and cracks on the structure of the moulded parts. The optimum moulding parameters of the feed stocks for the zigzag shaped mold are determined to be at an injection pressure of 80 to $140 \mathrm{MPa}$ at barrel temperature of 190 to $230^{\circ} \mathrm{C}$ [8]. When a property of powder injection moulded steatites is investigated, sintered at $1300^{\circ} \mathrm{C}$ for 4 hours, a theoretical density of $98 \%-99 \%$ is achieved. Three-point bending and tensile test was performed on the samples sintered at $1200^{\circ} \mathrm{C}$ to $1300^{\circ} \mathrm{C}$. The maximum 
three-point bending and tensile strength values are found to be $154 \mathrm{MPa}$ and $47 \mathrm{Mpa}$, respectively [9]. Indian steatite, mined in Rajasthan and Andhra Pradesh, is comparable with the best quality available in other countries. The steatite mined in India, with more than $92 \%$ brightness, less than $1 \%$ $\mathrm{Fe}_{2} \mathrm{O}_{3}$, and less than $1.5 \% \mathrm{CaCO}_{3}$, is preferred for exports [2]. Indian steatite is considered to be the second best in the world next to "Italian steatite." The UFSP used in this experiment develops M-S-H gel; hence the comparative study of C-S$\mathrm{H}$ and $\mathrm{M}-\mathrm{S}-\mathrm{H}$ is vital. On account of the basic structural difference between the two gel types, M-S-H and C-S-H are essentially immiscible [10]. Magnesium hydroxide $\left(\mathrm{Mg}(\mathrm{OH})_{2}\right.$ aka brucite) is a good starting point for the development of low $\mathrm{pH}$ cements. $\mathrm{pH}$ value of excess brucite in equilibrium with water is calculated to be around $\mathrm{pH} 10.5$ [11]. Hence, in principle, cement based on the hydration of $\mathrm{MgO}$ powder, calcined at low temperature to ensure fast hydration, should yield the desirable $\mathrm{pH}$. According to Zhang et al. [11] high $\mathrm{MgO}$ contents do not affect the $\mathrm{pH}$, whereas high silica fume content results in a $\mathrm{pH}$ closer to 9.5. Both $\mathrm{MgO}$ and silica fume composition have potential applications for the encapsulation of wastes containing heavy metals [11]. In the present research work, effect of UFNSP powder on setting time and strength development on cement is investigated.

\section{Materials and Experimental Methods}

\subsection{Raw Materials}

Cement. Ordinary portland cement conforming to IS: 81121989 (Indian Standard Designation, IS: 8112-1989) is used for mortar mixtures; the cement used in this study belongs to type I of ASTM. The physical and chemical properties are given in Table 1.

Fine Aggregates. Standard natural sand having hard, clean, strong, durable, uncoated particles and meeting the requirements of the specifications (ASTM C144-11) with specific gravity of 2.65 is used as fine aggregate.

Water. In the present investigation, potable water is used for mixing and curing.

Mineral Admixture. UFNSP obtained from UltraFine Mineral Pvt. Ltd., India, is used as natural admixture. UFNSP is manufactured by using high quality crushers and superfine grinders. UFNSP is finer than cement. The physical and chemical properties are given in Table 1.

2.2. Consistency of Cement. The basic aim is to find out the water content required to produce a cement paste of standard consistency as specified by the IS: 4031 (Part 4)-1988. The principle is that standard consistency of cement is that consistency at which the Vicat plunger penetrates to a point 5-7 $\mathrm{mm}$ from the bottom of Vicat apparatus, conforming to IS: 5513-1976. Approximately $400 \mathrm{~g}$ of cement is mixed with a weighed quantity of water. The time of gauging should be between 3 and 5 minutes. Fill the Vicat mould with paste and level it with a trowel. Lower the plunger gently till it touches the cement surface. Then release the plunger to sink into the paste. Note the reading on the gauge and repeat the above procedure taking fresh samples of cement and different quantities of water until the reading on the gauge is 5 to $7 \mathrm{~mm}$.

2.3. Initial and Final Setting Time (IST and FST). How to calculate the initial and final setting time as per IS: 4031 (Part 5)-1988 by Vicat apparatus conforming to IS: 5513-1976? Prepare a cement paste by gauging the cement with 0.85 times the water required to give a paste of standard consistency. Start a stopwatch the moment water is added to the cement. Fill the Vicat mould completely with the cement paste gauged as above. With the mould resting on a nonporous plate, smooth off the surface of the paste making it level with the top of the mould. The cement block thus prepared in the mould is the test block.

Determining Initial Setting Time (IST). Place the test block under the rod bearing the needle. Lower the needle gently in order to make contact with the surface of the cement paste. Release quickly, allowing it to penetrate the test block. Repeat the procedure till the needle fails to pierce the test block to a point $5.0 \pm 0.5 \mathrm{~mm}$ measured from the bottom of the mould. Initial setting time is the period elapsing when water is added to the cement and the needle fails to pierce the test block by $5.0 \pm 0.5 \mathrm{~mm}$ measured from the bottom of the mould.

Final Setting Time (FST). Replace the above needle by the one with an annular attachment. The cement is considered to finally set, when the gentle application of the needle makes an impression therein, while the attachment fails to do so. Final setting time is the period elapsing when water is added and the needle makes an impression on the surface of the test block.

2.4. Compressive Strength on Mortar Cubes. Mortar cubes used in this investigation were $70.6 \mathrm{~mm} \times 70.6 \mathrm{~mm} \times$ $70.6 \mathrm{~mm}$ confirming to IS $10080-1982$. The specimens were prepared in ratio of cement : sand as $1: 3$ and $\mathrm{W} / \mathrm{B}$ ratio as 0.47 . These specimens are cast in three layers, in accordance to IS 10080-1982. Each layer is well compacted by a tamping rod of $12 \mathrm{~mm}$ diameter. After the compaction the top surface is leveled using a trowel and left for 24 hours to dry in room temperature of $28^{\circ} \mathrm{C}$ with $60 \%$ humidity. On the next day, at room temperature of $29^{\circ} \mathrm{C}$ and $54 \%$ humidity, the mortar cubes are kept inside a curing tank filled with portable water. The specimens are tested with a $2000 \mathrm{kN}$ capacity hydraulic compression testing machine, as per IS: $4031-1982$ (Part 6). Altogether 108 mortar cubes ( 6 Mix IDs $\times 18$ specimens) were cast and were tested for compressive strength.

\subsection{Scanning Electron Microscopy and X-Ray Diffraction} Studies. The specimen is studied by Scanning Electron Microscopy and XRD Patterns. Samples for scanning electron microscopy (SEM) analysis are taken near the surface (0$1 \mathrm{~mm}$ depth) of specimens. Micro structural studies utilized SEM (HITACHI S-3000H, Japan) equipped with EDAX analyzer for micro structural observations of the surfaces, which 
TABLE 1: Physical and chemical properties of cement and UFNSP.

\begin{tabular}{lcc}
\hline & Cement & UFNSP \\
\hline \multicolumn{3}{c}{ Physical properties } \\
Blaine surface area $\left(\mathrm{m}^{2} / \mathrm{Kg}\right)$ & 380 & 750 \\
Particle mean dia. $(\mu \mathrm{m})$ & $<32$ & $<5$ \\
Density & 3.1 & 2.7 \\
Loss of ignition & $2 \%$ & $3.33 \%$ \\
\hline \multicolumn{3}{c}{ Chemical properties } \\
$\mathrm{SiO}_{2}$ & $23 \%$ \\
$\mathrm{Al}_{2} \mathrm{O}_{3}$ & $4.20 \%$ & $62.67 \%$ \\
$\mathrm{MgO}$ & $0.20 \%$ & $0.24 \%$ \\
$\mathrm{Fe}_{2} \mathrm{O}_{3}$ & $1.20 \%$ & $33.26 \%$ \\
$\mathrm{CaO}$ & $63 \%$ & $0.30 \%$ \\
\end{tabular}

is coated with evaporated copper for examination. SEM analyses is done at a maximum magnification of $20,000 \mathrm{x}$ with energy $15 \mathrm{keV}$ and a high resolution of $3.5 \mathrm{~nm}$. For this analysis, samples of size $10 \mathrm{~mm}$ cubes are cut with a saw cutter on 28th day. The XRD analysis is carried out with a Siemens $\mathrm{D}-5000 \mathrm{X}$-ray diffractometer with $\mathrm{Cu} \mathrm{K}$-beta radiation and $2 \theta$ scanning with a step size of $0.02^{\circ}$ and a measuring time of 10.00 Deg/minute. A voltage of $40 \mathrm{kV}$ and current of $15 \mathrm{Ma}$ is used. Samples are collected from the cubes after 28 days of water curing and powdered in ball mills to pass through the sieve size of $90 \mu$.

\section{Results and Discussions}

3.1. Consistency of Cement. From Table 2 the consistency of binder material is observed. The consistency is found to continuously increase as the percentage replacement of cement with UFNSP increases. The water consistency increases for C5, C10, C15, C20 and C25 at 4\%, 5\%,7\%, 10\%, 13\% when compared with $\mathrm{C} 0$. This may be due to higher fineness of UFNSP and higher water absorption property.

3.2. Setting Time. From the experimental design, the maximum, minimum and average values of IST and FST are shown in Table 2, together with the main effects and UFNSP interactions. The values are reported as relative values with respect to ordinary Portland cement paste, 30 and 360 minutes for IST and FST respectively. The IST for C5, C10, $\mathrm{C} 15$ and C20 decreases by 5minutes, 10 minutes, 10 minutes, and 5 minutes respectively and for C25 IST increases by 10 minutes when compared with C0 mix. Similarly the FST for C5, C10, C15 and C20 decreases by 30 minutes, 60 minutes, 60 minutes, and 30 minutes respectively and for C25 FST increases by 90 minutes when compared with $\mathrm{C} 0$ mix. From the above results it is observed that IST and FST decreases when percentage of UFNSP replacement increases up to $20 \%$, but there is a sudden increase in IST and FST on C25 specimen which may be due to excess UFNSP.

3.3. Compressive Strength of Mortar Cubes. The strength attained during 3 days, 7 days and 28 days on mortar cubes are

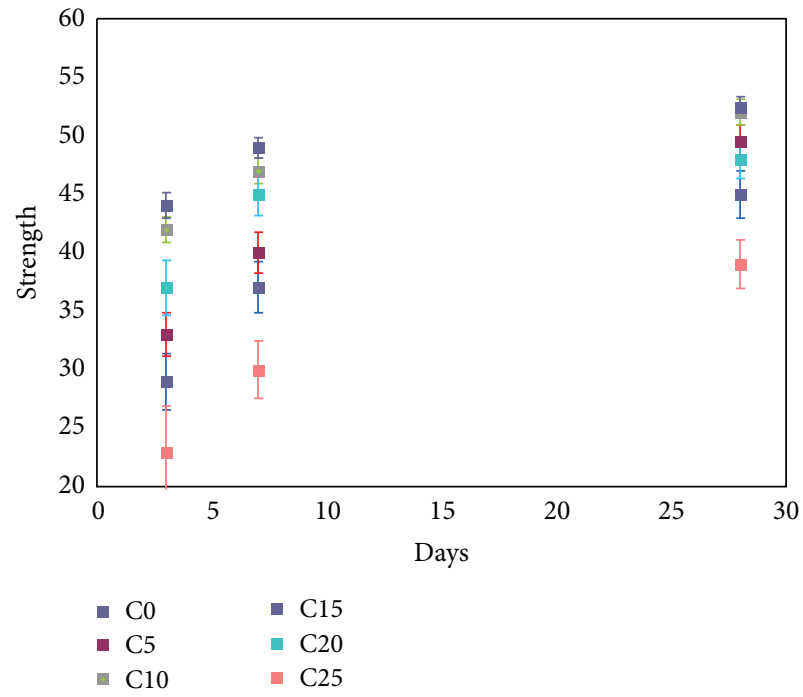

FIGURE 1: Scatter plot on strength of mortar cubes with standard deviation.

experimentally tested for 6 specimens on each age and their average results are shown in Table 3 and Figure 1 . The strength of mortar cubes of C5, C10, C15, C20 and C25 are compared with $\mathrm{C} 0$ mix. The compressive strength on 3 days for $\mathrm{C} 5, \mathrm{C} 10$, $\mathrm{C} 15$ and $\mathrm{C} 20$ increases by $13.8 \%, 44.8 \%, 51.7 \%$ and $27.5 \%$. The strength of C25 decreases by $20.7 \%$. On the 7 th day for C5, C10, C15 and C20 increase by $8.1 \%, 27.02 \%, 32.43 \%$ and $21.6 \%$. The strength of C25 decreases by $18.9 \%$ and on the 28 th day for C5, C10, C15 and C20 increases by 10\%, 15.6\%, 16.7\% and $6.7 \%$. The strength of $\mathrm{C} 25$ decreases by $13.3 \%$. Thus the above results show the Mix C5, C10, $\mathrm{C} 15$ has a considerable increase in terms of strength and also the strength is easily attained on its early ages like 3 days and 7 days. Data on the variation in compressive strength of mortar cubes is shown in Table 3 and Figure 1. The Standard Deviation (SD) and Coefficient of Variation (CO-VAR) of the compressive strength on 3 days, 7 days and 28 days shows decrease in SD and CO-VAR with increase in ages. The maximum SD is observed in $\mathrm{C} 25$, the lowest SD is observed at C10 and C15. The SD for C0 and C20 shows almost equal values. C5 shows lesser SD than C0 but more than $\mathrm{C} 10$ on all age. The CO-VAR fell from maximum value on 3 days to the lowest on 28 days for all specimens. The data shows that C15 is the specimen having Lowest SD and CO-VAR, with maximum strength, which also ensures that $\mathrm{C} 15 \mathrm{mix}$ is the most reliable of all mix IDs. The C25 specimens have highest SD and CO-VAR and lowest strength and are identified as the inferior specimen of all other specimen.

3.4. Microstructural Analysis. The results obtained in SEM and XRD analysis are shown in Figures 2 and 3.

The analysis shows that the best results are obtained from adding $15 \%$ of UFNSP. The images obtained in SEM are shown in Figure 2. Figure 2(a) shows the micrograph of C0; it consists of fine particles, which appear to have agglomerated into larger groups of particles. Figure 2(b) shows the micrograph of C5 specimen; the extent of coverage is substantial but not 
TABLE 2: Consistency, IST, and FST.

\begin{tabular}{lccccc}
\hline S. number & Mix IDs & \% replacement of UFNSP & \% consistency of water for binder & IST in minutes & FST in minutes \\
\hline 1 & C0 & 0 & 24 & 30 & 25 \\
2 & C5 & 5 & 28 & 20 & 360 \\
3 & C10 & 10 & 29 & 20 & 330 \\
4 & C15 & 15 & 31 & 25 & 300 \\
5 & C20 & 20 & 37 & 40 & 330 \\
6 & C25 & 25 & 350 \\
\hline
\end{tabular}

TABLE 3: Compressive strength of mortar cubes.

\begin{tabular}{lcccccccccc}
\hline S. number & Mix IDs & $\begin{array}{c}\text { 3-day } \\
\text { strength in } \\
\text { MPa }\end{array}$ & SD in MPa & $\begin{array}{c}\text { CO-VAR } \\
\text { in \% }\end{array}$ & $\begin{array}{c}\text { 7-day } \\
\text { strength in } \\
\text { MPa }\end{array}$ & SD in MPa & $\begin{array}{c}\text { CO-VAR } \\
\text { in \% }\end{array}$ & $\begin{array}{c}\text { 28-day } \\
\text { strength in } \\
\text { MPa }\end{array}$ & $\begin{array}{c}\text { SD in MPa } \\
\text { CO-VAR } \\
\text { in \% }\end{array}$ \\
\hline 1 & C0 & 29.00 & 2.39 & 8.23 & 37.00 & 2.19 & 5.92 & 45.00 & 2.00 & 4.44 \\
2 & C5 & 33.00 & 1.90 & 5.75 & 40.00 & 1.79 & 4.47 & 49.50 & 1.38 & 2.78 \\
3 & C10 & 42.00 & 1.10 & 2.61 & 47.00 & 1.10 & 2.33 & 52.00 & 1.10 & 2.11 \\
4 & C15 & 44.00 & 1.10 & 2.49 & 49.00 & 0.89 & 1.83 & 52.50 & 0.84 & 1.59 \\
5 & C20 & 37.00 & 2.37 & 6.40 & 45.00 & 1.79 & 3.98 & 48.00 & 1.67 & 3.49 \\
6 & C25 & 23.00 & 3.90 & 16.95 & 30.00 & 2.45 & 8.16 & 39.00 & 2.10 & 5.38 \\
\hline
\end{tabular}

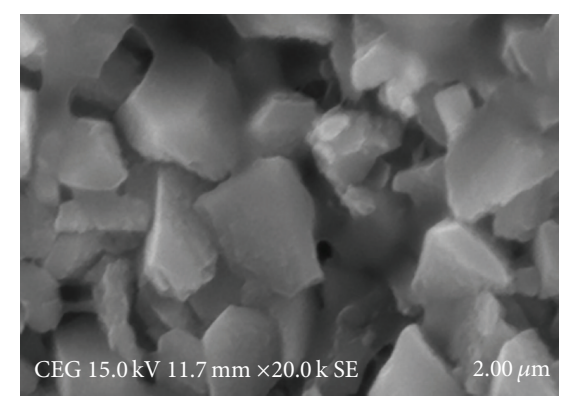

(a)

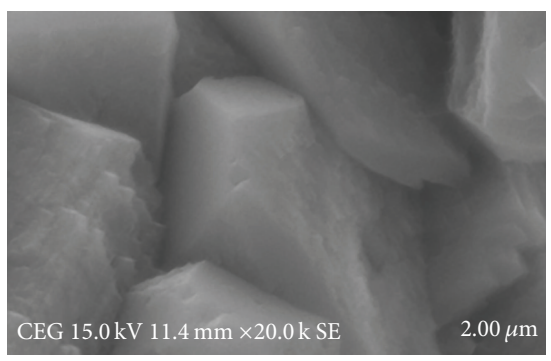

(d)

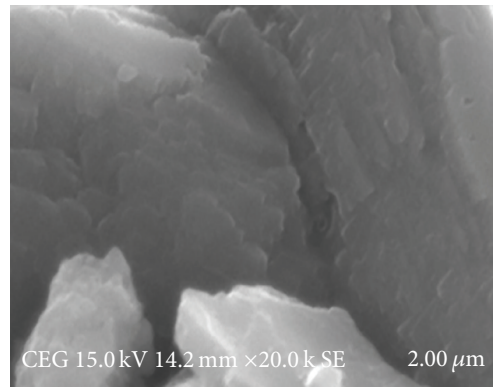

(b)

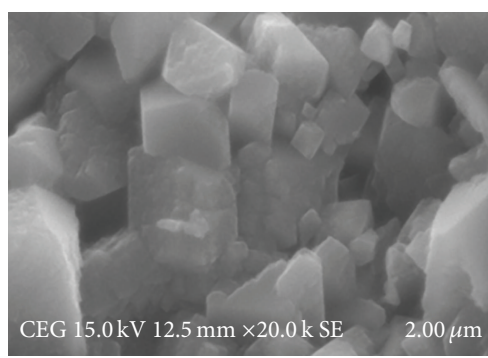

(e)

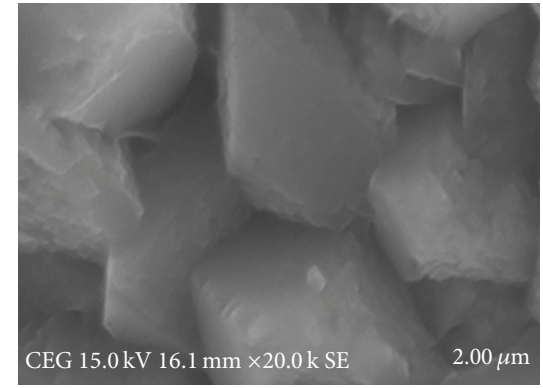

(c)

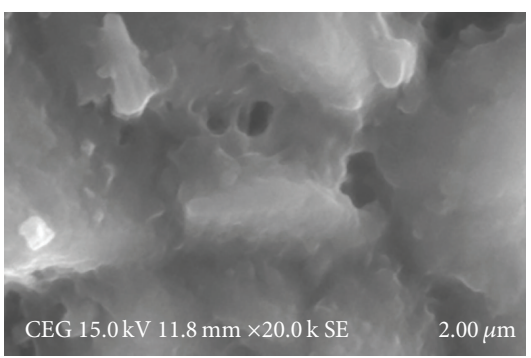

(f)

Figure 2: SEM images of specimens with $20000 \mathrm{x}$ magnification: (a) C0 specimen, (b) C5 specimen, (c) C10 specimen, (d) C15 specimen, (e) C20 specimen, and (f) C25 specimen.

enough material has formed to create a continuous film on the surface of the particle. Some regions show the traces of no hydration products and absence of deposition of hydration products. Figures $2(\mathrm{c})$ and $2(\mathrm{~d})$ show the micrograph of C10 and C15 specimens, respectively. This shows that due to the abundance of the hydration products the appearance has changed from small isolated particles to tangled web of flake-like crystals. The hydration products consist of a mixture of phases as is typical for portland cement. For example, portlandite is visible at some regions, intermixed with reticulated C-S-H (or) M-S-H gel. Figure 2(e) shows the micrograph of $\mathrm{C} 20$; it is similar to that of $\mathrm{C} 0$; but there are no empty regions without hydration products, and hence this C20 specimen mechanical behaviour is similar to that of C0. Figure 2(f) shows the micrograph of C25 specimen; this shows that the flake-like crystals start disappearing and form into cloudy disintegrated form. This also confirms the loss in bonding effect. A study on microstructure of samples 

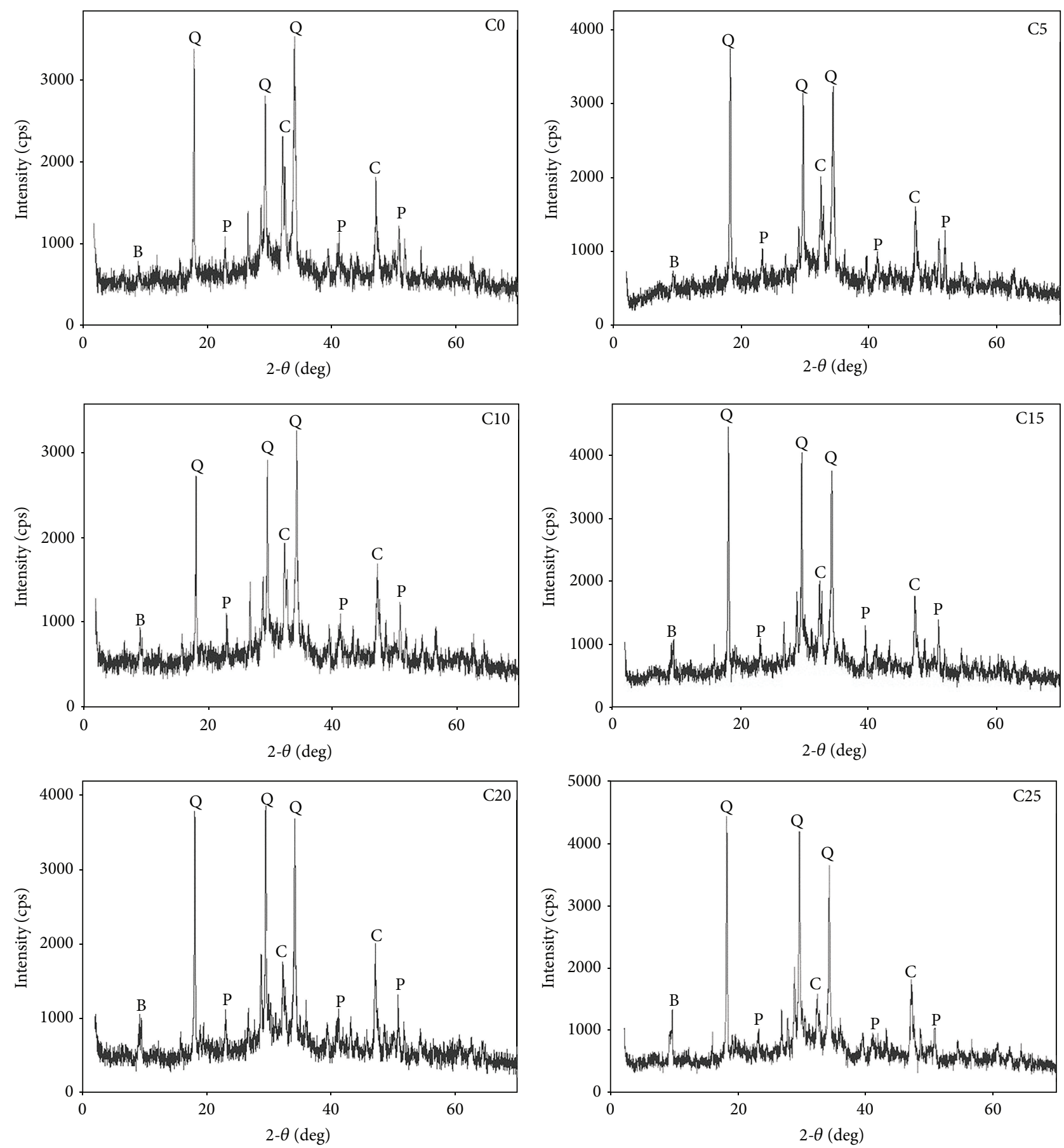

FIgURE 3: XRD patterns of C0, C5, C10, C15, C20, and C25 mortars. Q: quartz; C: calcite; P: portlandite; B: brucite.

$\mathrm{C} 0, \mathrm{C} 5, \mathrm{C} 10, \mathrm{C} 15, \mathrm{C} 20$, and $\mathrm{C} 25$ is made. The results show that the UFNSP particles have been covered in a continuous pattern for C5, C10, and C15 specimens and pattern of very small particles is identified for C20 and C25 specimens. The patterns for $\mathrm{C} 20$ specimen are similar to $\mathrm{C} 0$ specimen. The C25 specimen shows lack of bonding and formation of independent particles without bond, which may be the cause of reduction in strength.
Figure 3 shows the X-ray diffrograms of C0, C5, C10, C15, $\mathrm{C} 20$, and $\mathrm{C} 25$ mortars, respectively. The main compounds are quartz $\left(\mathrm{SiO}_{2}\right)$, calcite $\left(\mathrm{CaCO}_{3}\right)$, portlandite $\left(\mathrm{Ca}(\mathrm{OH})_{2}\right)$, and brucite $\left(\mathrm{Mg}(\mathrm{OH})_{2}\right)$. The X-ray diffrograms show increase in quartz when UFNSP is added. The calcite is similar in all specimens. The intensity of brucite increases as percentage replacement of UFNSP increases. The peaks for all specimens indicate the presence of quartz, calcite, and portlandite and 
very small quantity of brucite. The intensity of portlandite peak is slightly higher in $\mathrm{C} 10$ and $\mathrm{C} 15$ when compared to other specimens.

The increase in $\mathrm{C} 15$ strength is due to the right combination of portlandite, calcite, and brucite. The SEM image and X-ray diffrograms (Figures 2(d) and 3) of C15 show the wider presence of dense portlandite and brucite which supports faster hydration reaction. The reduction in calcite leads to decrease in carbonation process. Hence maximum strength is attained in C15. Figure 3 shows that the intensity of portlandite is very low for $\mathrm{C} 25$. The increase of brucite $\left(\mathrm{Mg}(\mathrm{OH})_{2}\right)$ in combination with reduction of portlandite leads to the conclusion that portlandite most probably reacted with magnesium. The very low solubility of brucite favours the consumption of calcium hydroxide $\left(\mathrm{Ca}(\mathrm{OH})_{2}\right)$ [12]. The reduction in strength of $\mathrm{C} 25$ specimen is attributed to the pozzolanic activity and pore structure. Since replacement of UFNSP reduces the content of portlandite, the hydration reaction and pozzolanic activity decreases. Hence the strength contribution from this process is lower than $\mathrm{C}$.

\section{Conclusion}

From the present study it can be concluded that replacement of UFNSP with cement results in decrease of IST and FST, but the consistency of binding material increases. This shows the increase in requirement of water to produce cement paste. The compressive strength of mortar cube increases during its early stages. The maximum compressive strength in 3, 7, and 28 days is observed at $\mathrm{C} 15$. The improvement in strength in $\mathrm{C} 5, \mathrm{C} 10, \mathrm{C} 15$, and $\mathrm{C} 20$ is nominal at all stages and normalizes in 28 days. The C25 shows decrease in strength and increase in IST and FST. It is also observed that replacing UFNSP with cement results in improvement of microstructure of cement mortar. The C5, C10, and C15 specimens show denser microstructural bond when compared to other specimens. The availability of denser hydration product (portlandite) in $\mathrm{C} 15$ specimen is identified. The C20 specimen shows micro structural similarity to control specimen. The reduction in strength of C25 specimen is attributed to the pozzolanic activity and pore structure. C25 shows disintegrated microstructure and very low intensity of portlandite. From all the above discussion it is concluded that the suitable UFNSP replacement percentage should not exceed $20 \%$.

\section{Conflict of Interests}

The authors declare that there is no conflict of interests regarding the publication of this paper.

\section{Acknowledgments}

The authors of this paper express their gratitude to the management of Thiagarajar College of Engineering (TCE). The authors wish to express their thanks to the department for facilitating this work.

\section{References}

[1] C. Karatas, A. Kocer, H. I. Ünal, and S. Saritas, "Rheological properties of feedstocks prepared with steatite powder and polyethylene-based thermoplastic binders," Journal of Materials Processing Technology, vol. 152, no. 1, pp. 77-83, 2004.

[2] Ministry of mines, Indian Bureau of Mines, Indian Mineral Year Book, 2011.

[3] H. Gökçe, D. Aĝaoĝullari, M. L. Öveçoĝlu, I. Duman, and T. Boyraz, "Characterization of microstructural and thermal properties of steatite/cordierite ceramics prepared by using natural raw materials," Journal of the European Ceramic Society, vol. 31, no. 14, pp. 2741-2747, 2011.

[4] P. Rohan, K. Neufuss, J. Matějíček, J. Dubský, L. Prchlík, and C. Holzgartner, "Thermal and mechanical properties of cordierite, mullite and steatite produced by plasma spraying," Ceramics International, vol. 30, no. 4, pp. 597-603, 2004.

[5] F. P. Cota, R. A. A. Alves, T. H. Panzera, K. Strecker, A. L. Christoforo, and P. H. R. Borges, "Physical properties and microstructure of ceramic-polymer composites for restoration works," Materials Science and Engineering A, vol. 531, pp. 28-34, 2012.

[6] T. H. Panzera, K. Strecker, J. D. S. Miranda, A. L. Christoforo, and P. H. R. Borges, "Cement-steatite composites reinforced with carbon fibres: an alternative for restoration of Brazilian historical buildings," Materials Research, vol. 14, no. 1, pp. 118123, 2011.

[7] W. Mielcarek, D. Nowak-Woźny, and K. Prociów, "Correlation between $\mathrm{MgSiO}_{3}$ phases and mechanical durability of steatite ceramics," Journal of the European Ceramic Society, vol. 24, no. 15-16, pp. 3817-3821, 2004.

[8] S. Erguney, C. Karatas, H. I. Unal, and S. Saritas, "Investigation of the moldability parameters of PEG based steatite feedstocks by powder injection molding," International Polymer Processing, vol. 26, no. 2, pp. 143-149, 2011.

[9] L. Urtekin, I. Uslan, and B. Tuc, "Investigation of properties of powder injection-molded steatites," Journal of Materials Engineering and Performance, vol. 21, no. 3, pp. 358-365, 2012.

[10] D. R. M. Brew and F. P. Glasser, "Synthesis and characterisation of magnesium silicate hydrate gels," Cement and Concrete Research, vol. 35, no. 1, pp. 85-98, 2005.

[11] T. Zhang, C. R. Cheeseman, and L. J. Vandeperre, "Development of low $\mathrm{pH}$ cement systems forming magnesium silicate hydrate (M-S-H)," Cement and Concrete Research, vol. 41, no. 4, pp. 439442, 2011.

[12] Y. Senhadji, M. Mouli, H. Khelafi, and A. S. Benosman, "Sulfate attack of Algerian cement-based material with crushed limestone filler cured at different temperatures," Turkish Journal of Engineering and Environmental Sciences, vol. 34, no. 2, pp. 131143, 2010. 

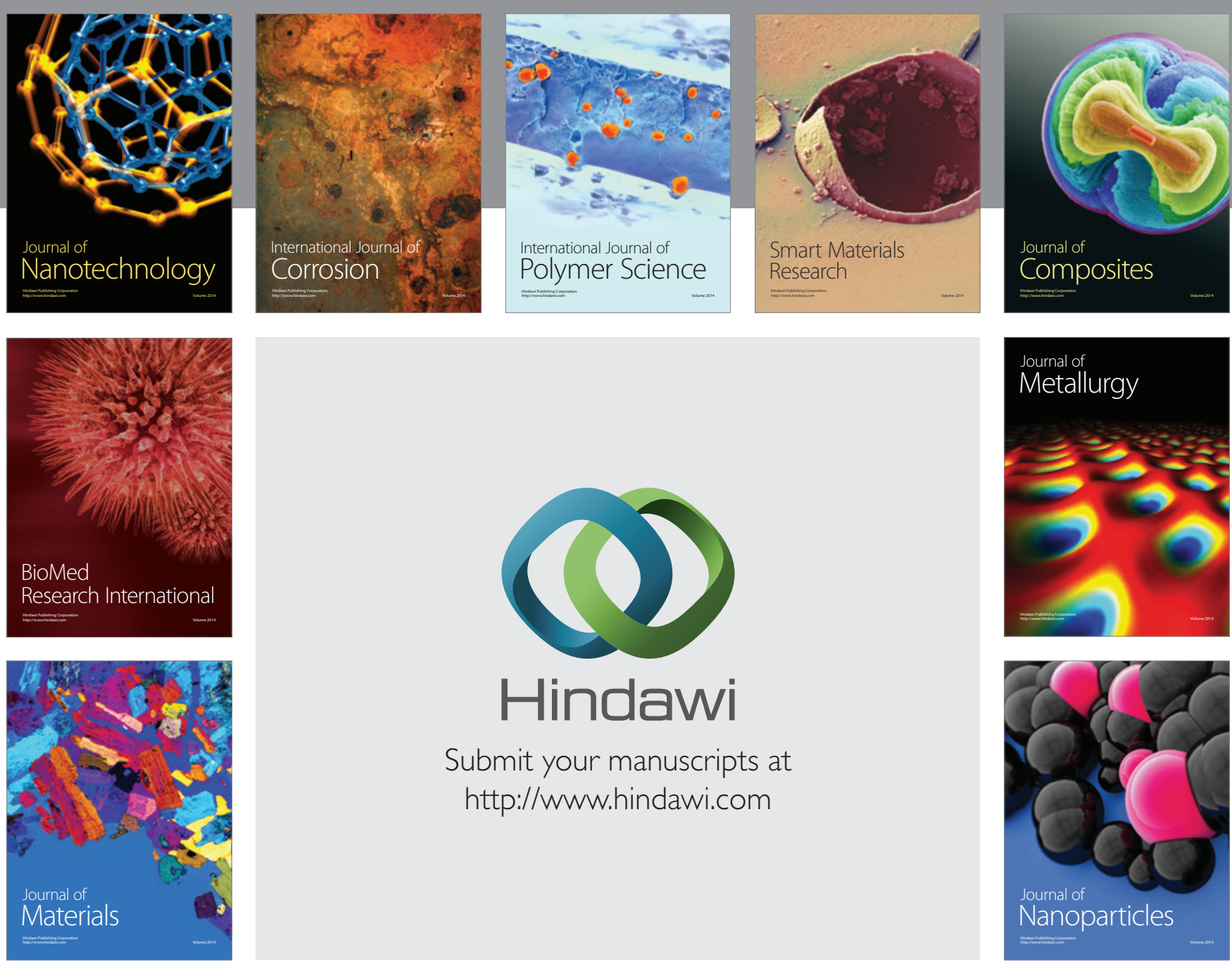

Submit your manuscripts at http://www.hindawi.com
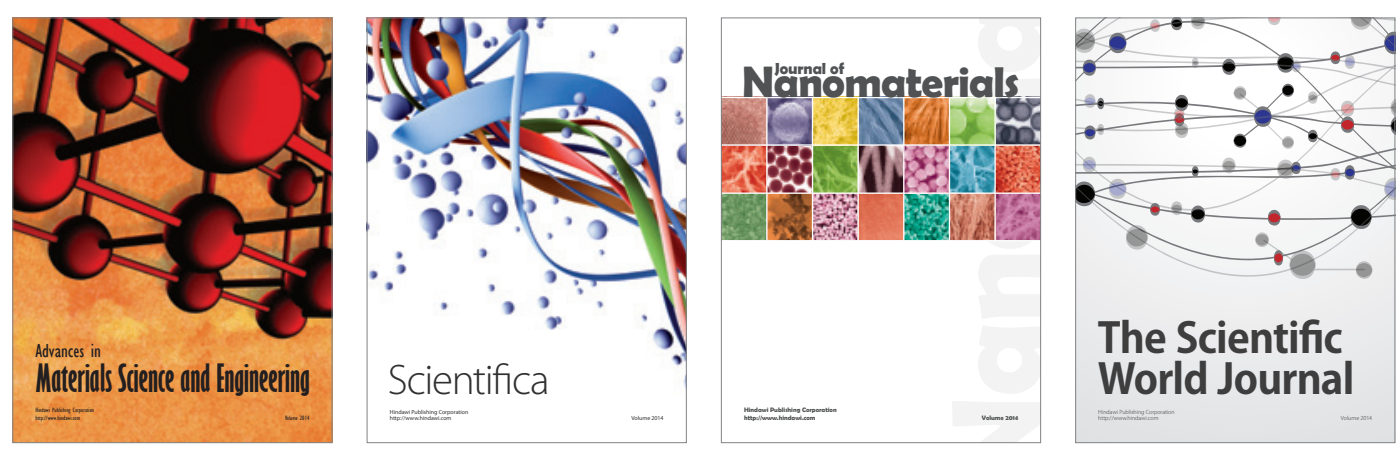

\section{The Scientific World Journal}
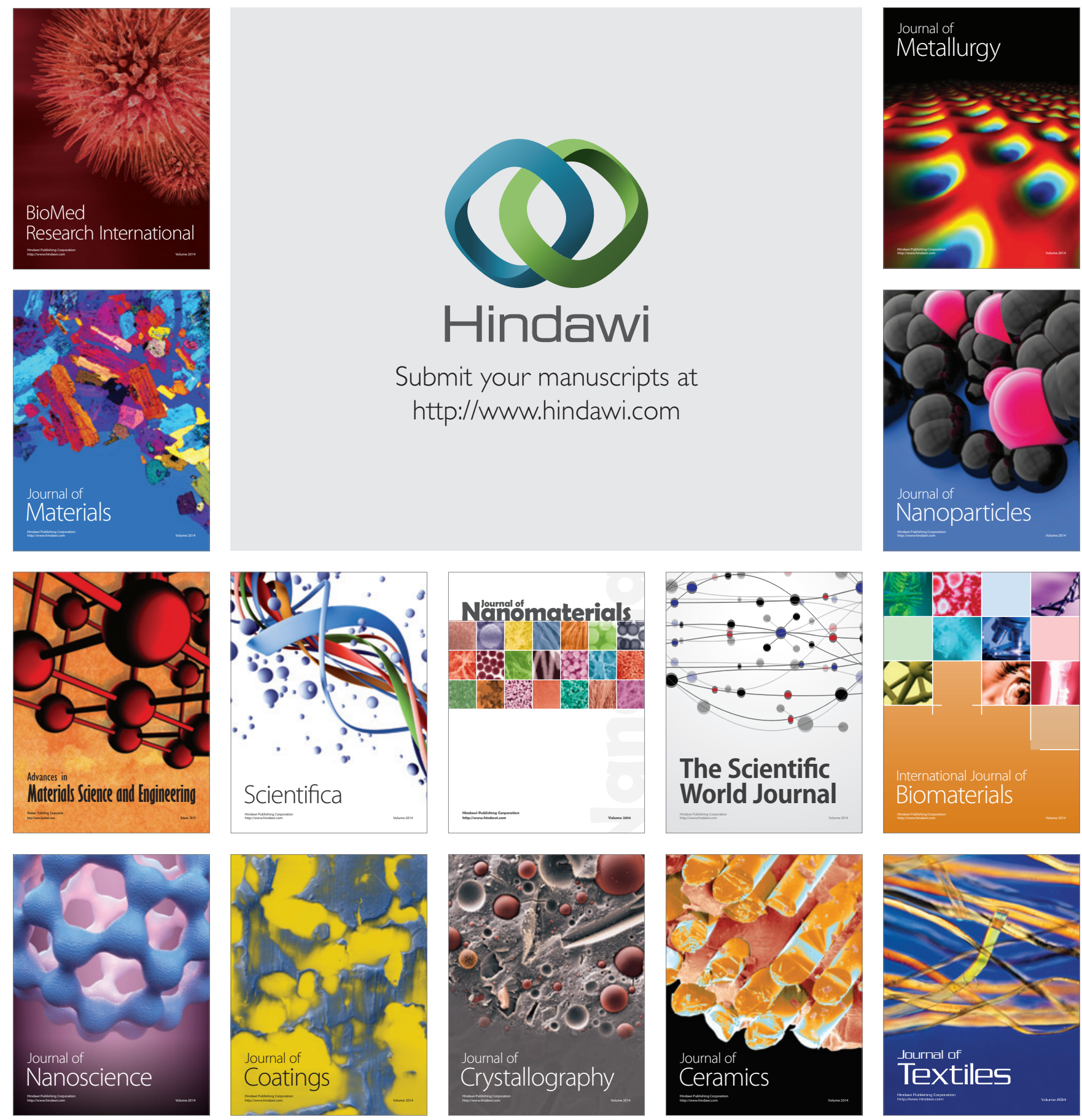